\title{
Epithelial membrane antigen in cells from the uterine cervix: immunocytochemical staining of cervical
}

\section{smears}

\author{
B VALKOVA,${ }^{*} \dagger$ MG ORMEROD,${ }^{*}$ D MONCRIEFF,${ }^{*} \ddagger$ DV COLEMAN $\dagger$ \\ From the *Institute of Cancer Research, Royal Cancer Hospital, The Haddow Laboratories, Sutton, Surrey, \\ and the †Department of Pathology, St Mary's Hospital Medical School, London W2
}

SUMMARY Smears made from cervical scrapes have been stained immunocytochemically for epithelial membrane antigen using a polyclonal antiserum and two monoclonal antibodies. With the polyclonal antiserum malignant cells and those showing dysplasia consistently expressed the antigen. Normal cells were generally negative, with the exception of some metaplastic cells. The monoclonal antibodies, although they stained the abnormal cells less consistently, gave the same pattern of staining. All three antibodies showed considerable heterogeneity in the intensity of stain. This appears to be a general feature of the expression of this type of epitope in epithelial cells.

While the results confirm that an immunohistochemical stain might have potential application for improved diagnostic methods, the staining of metaplastic cells with the presently available antibodies limits the usefulness of an antiserum to epithelial membrane antigen.

Epithelial membrane antigen (EMA) is found on the surfaces of many non-squamous epithelial tissues.' Its expression is often increased in neoplasia, and antisera to EMA are of value in diagnostic tumour pathology. ${ }^{2}$ EMA is not generally expressed by normal, mature squamous cells but is found in neoplastic epithelium. ${ }^{34}$ This observation prompted us to investigate the possible use of antisera to EMA for the diagnosis of cervical intraepithelial neoplasia (CIN) and invasive carcinoma of the cervix.

Immunocytochemical staining of cervical smears with a polyclonal antiserum to EMA showed a distribution of staining in which abnormal cells were stained while most of the normal cells in the smears were negative. ${ }^{56}$ This type of staining might be utilised in a procedure for automated screening, but, before exploring this further, more quantitative information about the pattern of staining is needed. It is also necessary to establish whether any variation in the pattern of staining is due to a heterogeneity in the expression of the antigen con-

Accepted for publication 21 May 1984

$\ddagger$ Present address: Department of Obstetrics and Gynecology, St George's Hospital, London SW17. cerned or whether it is due to a variation in expression of different epitopes being carried by different molecules. The latter possibility should be entertained since it is known that the reactive site of EMA contains carbohydrate.? We have therefore compared the pattern of staining obtained with the polyclonal antiserum with that obtained using monoclonal antibodies. An added reason for the comparison with monoclonal antibodies is that, for an immunocytochemical procedure to be used on a large scale, an indefinite supply of uniform antibodies would be desirable.

In a preliminary study we compared a series of monoclonal antibodies which reacted with EMA by using them to stain cervical smears. From these results we selected two monoclonal antibodies which showed the best specificity and used these for the more detailed study reported here. These two monoclonal antibodies came from a set raised against membranes from a human bladder carcinoma (Summerhayes and Pocock, unpublished observations). Jha $e t a l^{8}$, using an immunohistochemical stain of tissue sections, have shown that the antigens associated with these antibodies have a distribution similar to EMA in the cervix and in cervical neoplasia. 


\section{Material and methods}

\section{COLLECTION AND PREPARATION OF CERVICAL SMEARS}

Cervical smears were taken conventionally using a wooden Ayre spatula from 38 women attending family planning and gynaecology clinics. Two specimens were taken from each patient. The first was prepared for a conventional Papanicolau stain and the second for the immunocytochemistry. For the latter procedure the Ayre spatula was placed immediately in $5 \mathrm{ml}$ of Cellfix (Vickers mucus dissolving solution without carbowax). ${ }^{9}$ The samples were stored either in ice or at $4^{\circ} \mathrm{C}$ until they reached the laboratory. After agitation to dislodge the cells, the spatula was removed and the suspension was aspirated through a $19 \mathrm{G}$ needle in order to disaggregate any clumps of cells. After centrifugation and resuspension, the cells were washed twice in phosphate buffered saline (PBS); the final pellet was resuspended in an equal volume of PBS, and $20 \mu \mathrm{l}$ aliquots were spread on to clean microscope slides and air dried. Several smears were obtained from each sample and these were stored at $-20^{\circ} \mathrm{C}$.

\section{ANTISERA}

The polyclonal antiserum to EMA was raised in a rabbit and absorbed as described previously. ${ }^{110}$

The monoclonal antibodies $77 \cdot 1$ and $80 \cdot 30 \cdot 3$ were a gift from Dr IC Summerhayes of the Institute of Cancer Research. A set of monoclonal antibodies reacting with human bladder was obtained by the hybridoma technique using spleen cells from mice immunised with membranes prepared from a lung metastasis of a human carcinoma of the bladder (Summerhayes and Pocock, unpublished observations). The set of antibodies was screened in our radioimmunoassay for $\mathrm{EMA}^{7}$ (Ormerod et al, unpublished observations) and the two which reacted with EMA were selected.

The second antibodies were affinity purified from a sheep antirabbit and a goat antimouse IgG serum and were conjugated to alkaline phosphatase.

\section{IMMUNOCYTOCHEMICAL STAINING ${ }^{\prime \prime}$}

After treatment for $5 \mathrm{~min}$ with $20 \%$ acetic acid to block any endogenous enzyme activity, the smears were washed, incubated with a suitable dilution of the first antibody for $1 \mathrm{~h}$, washed again, and incubated with the conjugated second antibody for a further hour. After another wash, the stains were developed in a solution of naphthol AS:BI phosphate plus brentamine fast red to give a red reaction product. The smears were counterstained with Mayer's haemalum.

In each batch a section of human kidney was included as a positive control (the distal and collecting tubules express EMA ${ }^{10}$ ) in order to monitor the strength of the stain. As a negative control for the polyclonal antiserum, a few duplicates of positive smears were stained with antiserum which had been absorbed with EMA. For the monoclonal antibodies, in each run, some smears stained without primary antibody. The most convincing negative control was supplied in the experimental smears themselves with the observation of negative normal cells alongside positive dyskaryotic cells (Fig. 1).

\section{INTERPRETATION OF THE STAIN}

The Papanicolau stained smears were read routinely and when abnormal cells were recorded the patients underwent colposcopy and a biopsy specimen was taken. Diagnosis of cervical intraepithelial neoplasia was made histopathologically.

In the alkaline phosphatase stained smears cells in which the cytoplasm was an intense red were characterised as staining strongly while those with a less intense cytoplasmic colour or which showed staining of the cell membrane only were classified as staining weakly. The staining pattern from individual cells was recorded together with any indication of dyskaryosis or malignancy as shown by the appearance of the counterstained nucleus.

The results were analysed in two ways. First, each smear was carefully scanned, the cells classified, and the number of smears containing negative, weakly stained, or positive cells of each type recorded. Secondly, a set of smears from normal cases and a set from patients diagnosed as having CIN 3 were taken, and the number of stained or unstained cells of each type was counted. Some of these data are summarised in the histograms in Fig. 2.

\section{Results}

On the basis of the Papanicolau stain, 10 of the 38 cases examined were classified as normal, seven diagnosed as CIN 1, 19 as CIN 2 and 3, and two as invasive carcinoma.

An immunocytochemical stain of some cervical epithelial cells is shown in Fig. 1, which shows a dyskaryotic cell stained for EMA while the neighbouring normal cell is negative.

NEGATIVE SMEARS $(\mathrm{n}=10)$

In five smears all the superficial and intermediate cells were negative with all three antibodies. In one smear a few superficial cells stained weakly for EMA, and in the remaining four smears a small percentage of these cells stained with each of the antibodies. 


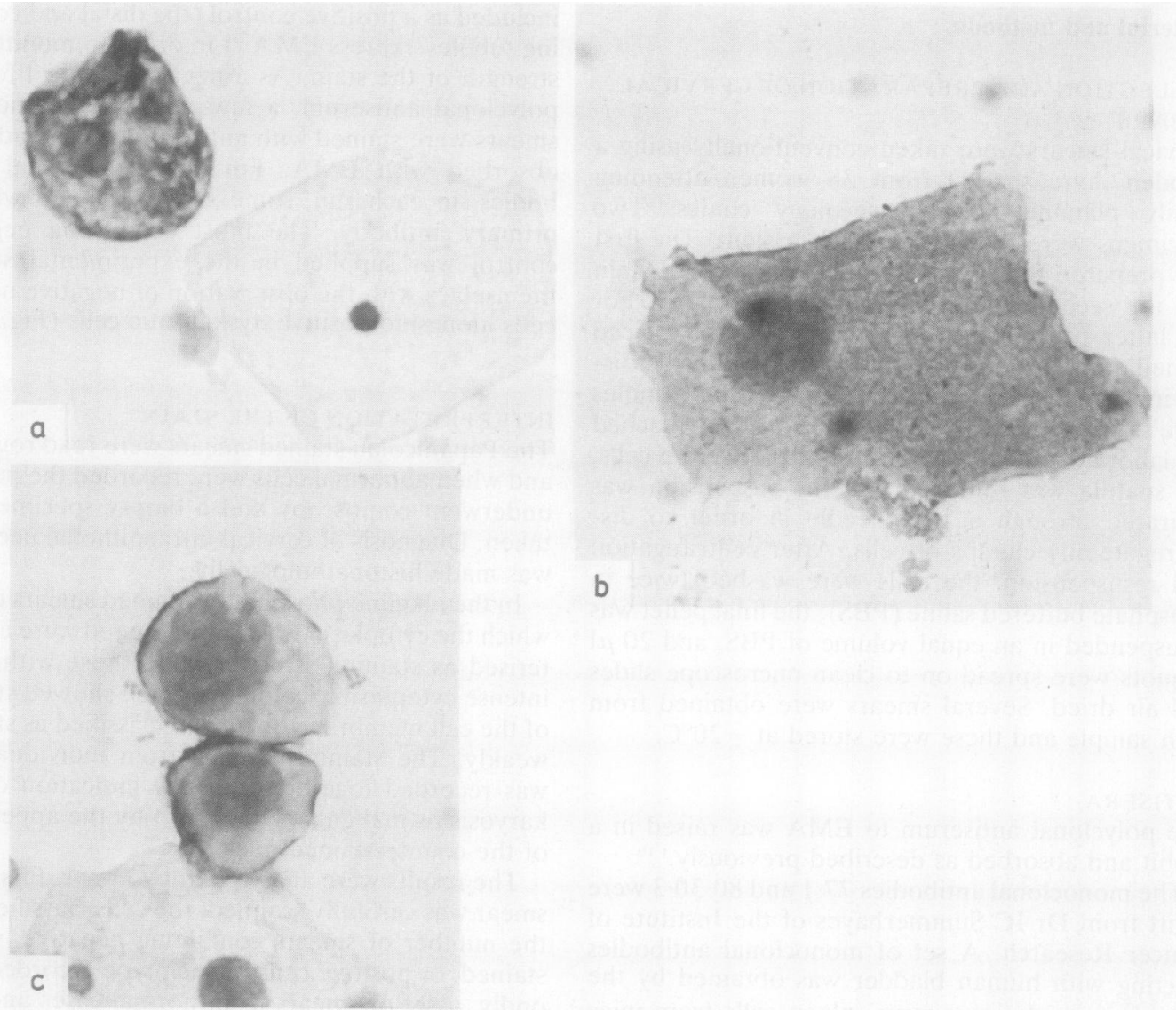

Fig. 1 Cervical smears from cases diagnosed as CIN 3 stained with a polyclonal antibody against epithelial membrane antigen $(E M A)$. (a) Antibody dilution =1/100. The smaller cell with an enlarged nucleus is stained while the larger normal squamous cell alongside is negative. $\times 1000$. (b) and (c) Antibody dilution $=1 / 500$. (b) Metaplastic cell with an even stain of the cytoplasm. (c) Two cells with dyskaryotic nuclei with strongly stained membranes. $\times 2000$.

In all the smears most of the intermediate cells were negative for all three antibodies. In six smears, however, a few intermediate cells stained weakly for EMA and in one a few cells stained strongly.

In all the smears some of the metaplastic cells stained for EMA, and in six cases there were some strongly staining cells present. Monoclonal antibodies 77.1 showed a similar staining pattern; with $80 \cdot 30 \cdot 3$ the pattern of staining of these cells was generally weaker, and in five of the smears all metaplastic cells were negative.

Endocervical cells were found in only a few smears and these were always negative.

The distribution of cells in each category after staining with the three antibodies did not differ significantly from that shown for the superficial, intermediate and metaplastic cells in cases of CIN 2 and 3 shown in Fig. 2. The number of superficial and intermediate cells exhibiting any stain was small; only the metaplastic cells contained an appreciable positive population.

\section{CIN $1(n=7)$}

The pattern of staining of the superficial and intermediate cells in cases diagnosed as CIN 1 was similar to that in the normal cases. Most cells were negative, but a few cells in some smears (three with EMA and $77 \cdot 1$, one with $80 \cdot 30 \cdot 3$ ) were stained. Similarly, the staining of the metaplastic cells did not differ significantly from that seen in the normal cases.

In every smear showing changes suggestive of CIN 1, the majority of dyskaryotic cells stained posi- 


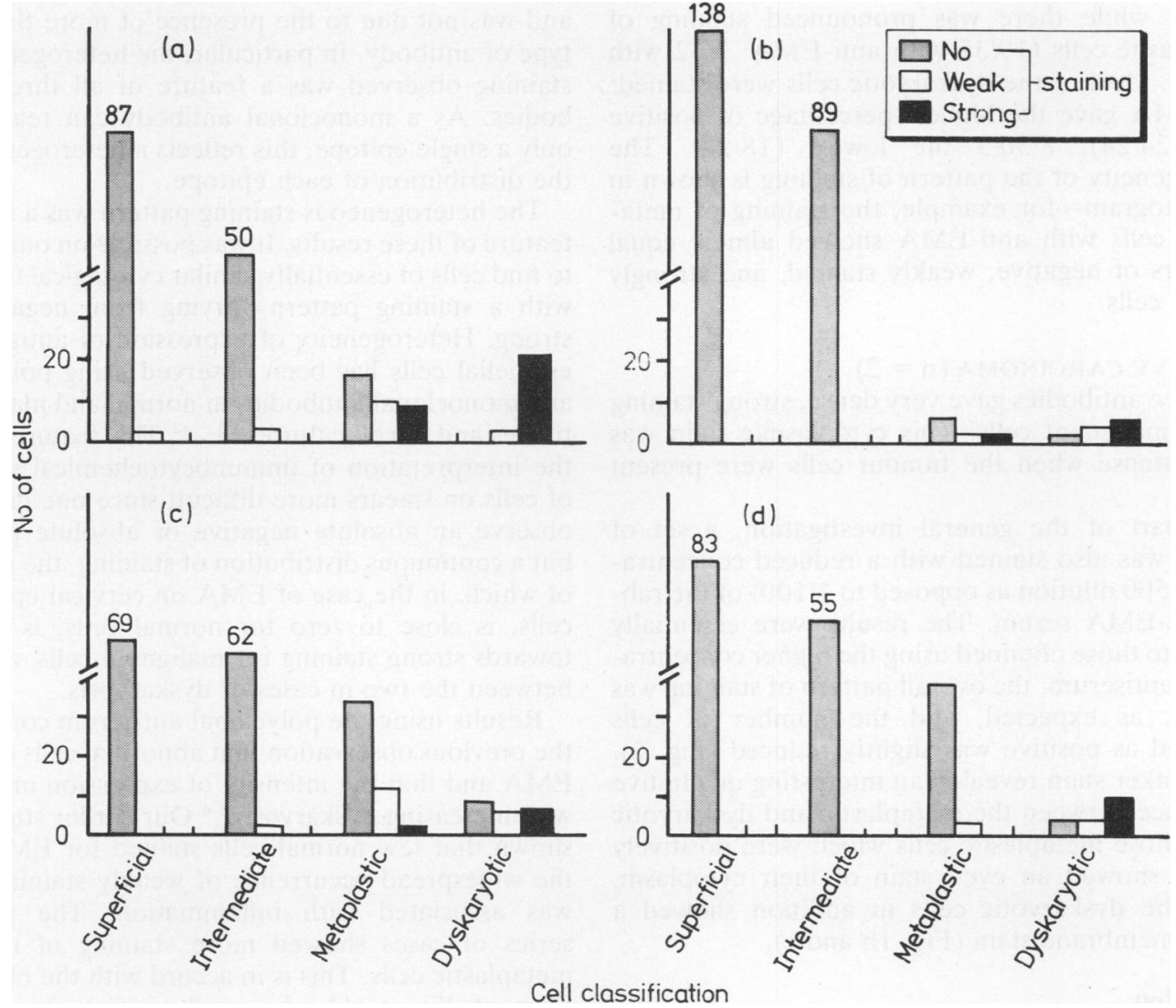

Fig. 2 Histogram showing the distribution of cells and the distribution of staining among different cells in smears from six cases diagnosed as CIN 2 or 3 . For each antibody a total of 200 cells was recorded. Cells stained with: (a) polyclonal anti-EMA (1/100); (b) polyclonal anti-EMA (1/500); (c) monoclonal antibody $77 \cdot 1 ;(d)$ monoclonal antibody $8 \cdot 30 \cdot 3$.

tively for EMA; in five cases the dyskaryotic cells were stained strongly by the antibody. The monoclonal antibodies stained these cells less consistently: in four smears treated with $77 \cdot 1$ and two treated with $8 \cdot 30 \cdot 3$ the dyskaryotic cells were unstained.

Few endocervical cells were found, and these were always negative.

\section{CIN 2 AND $3(n=19)$}

The distribution of stain in the superficial, intermediate, and metaplastic cells did not differ from that found in the other cases. The majority of the superficial and intermediate cells were negative: monoclonal antibody $8 \cdot 30 \cdot 3$ gave the weakest stain.

In all the smears dyskaryotic cells stained positively for EMA, and these included strongly staining cells in 17 cases. Monoclonal antibody $77 \cdot 1$ gave a similar but slightly weaker pattern of staining: only 12 smears exhibited strongly staining cells and 10 smears contained some negative cells. Monoclonal antibody $8 \cdot 30 \cdot 3$ gave even weaker staining, and in three smears none of the dyskaryotic cells was stained.

Only a few endocervical cells were found and these occasionally stained weakly for EMA and monoclonal antibody $77 \cdot 1$.

The distribution of cells in the different categories was estimated by scoring a total of 200 cells from six cases, which were selected because they contained examples of the major types of cell observed, including metaplastic cells. The results are shown in Fig. 2. Few superficial and intermediate cells stained (1/88 with anti-EMA; none with the monoclonal anti- 
bodies) while there was pronounced staining of metaplastic cells (19/37 with anti-EMA; $3 / 42$ with $8 \cdot 30 \cdot 3)$. Most of the dyskaryotic cells were stained: anti-EMA gave the highest percentage of positive cells $(24 / 24), 8 \cdot 30 \cdot 3$ the lowest $(18 / 22)$. The heterogeneity of the pattern of staining is shown in the histogram-for example, the staining of metaplastic cells with anti-EMA showed almost equal numbers of negative, weakly stained, and strongly stained cells.

INVASIVE CARCINOMA $(\mathrm{n}=2)$

All three antibodies gave very dense, strong staining of the malignant cells. This cytoplasmic stain was most intense when the tumour cells were present singly.

As part of the general investigation, a set of smears was also stained with a reduced concentration (1/500 dilution as opposed to $1 / 100)$ of the rabbit anti-EMA serum. The results were essentially similar to those obtained using the higher concentration of antiserum: the overall pattern of staining was weaker, as expected, and the number of cells recorded as positive was slightly reduced (Fig. 2). The weaker stain revealed an interesting qualitative difference between the metaplastic and dyskaryotic cells. Those metaplastic cells which were positively stained showed an even stain of their cytoplasm, while the dyskaryotic cells in addition showed a strong membrane stain (Fig. 1b and c).

\section{Discussion}

The monoclonal antibodies $77 \cdot 1$ and $8 \cdot 30 \cdot 3$ were from a set raised against membranes from a human bladder carcinoma. The urothelium of the bladder and tumours derived therefrom express EMA, and it was to be expected that some of the antibodies from this set should react with this antigen. We have now shown that both the monoclonal antibodies react with a disaccharide which can be found on EMA isolated from milk (Ormerod and Steele, unpublished observations). This is different from the antigenic determinant of the polyclonal antiserum, which contains both peptide and saccharide residues and includes the $\mathrm{O}$-glycosidic bond between protein and carbohydrate (Ormerod et al, unpublished observations). Our chemical studies have also indicated that the polyclonal antibodies in our antiserum react predominantly with a single epitope, and this is consistent with the present data. While the epitope for the polyclonal antibody was expressed more consistently, the overall pattern of staining with the three antibodies was similar, suggesting, but not proving, that the stain observed with the polyclonal antiserum was due to reaction with the one epitope and was not due to the presence of more than one type of antibody. In particular, the heterogeneity of staining observed was a feature of all three antibodies. As a monoclonal antibody can react with only a single epitope, this reflects a heterogeneity in the distribution of each epitope.

The heterogeneous staining pattern was a notable feature of these results. It was possible on one smear to find cells of essentially similar cytological features with a staining pattern varying from negative to strong. Heterogeneity of expression of antigens by epithelial cells has been observed using polyclonal and monoclonal antibodies in normal and malignant tissues and in cell cultures. ${ }^{12-14}$ This feature makes the interpretation of immunocytochemical staining of cells on smears more difficult since one does not observe an absolute negative or absolute positive but a continuous distribution of staining, the median of which, in the case of EMA on cervical epithelial cells, is close to zero for normal cells, is shifted towards strong staining for malignant cells, and lies between the two in cases of dyskaryosis.

Results using the polyclonal antiserum confirmed the previous observation that abnormal cells express EMA and that the intensity of expression increases with increasing dyskaryosis. ${ }^{56}$ Our earlier study had shown that few normal cells stained for EMA and the widespread occurrence of weakly staining cells was associated with inflammation. The present series of cases showed more staining of normal, metaplastic cells. This is in accord with the observations of Jha et al, ${ }^{8}$ who used several monoclonal antibodies against epithelial cells on tissue sections and found that metaplastic cells were often positive. Metaplastic cells also express the cervical tumour associated antigen described by Haines $e t$ al,,$^{15}$ which has a distribution in cervical cells similar to that of EMA.

The occasional staining of normal cells limits the potential value of an immunocytochemical stain for EMA in diagnosis, particularly as an aid to automation. In order to explore this aspect further, we need a quantitative measurement of the intensity of the stain and its distribution among the cells on the smear. Some preliminary work has already been reported, ${ }^{16}$ and we are now actively pursuing this approach using both flow cytometry of cell suspensions and automated microscopy.

The two monoclonal antibodies used in this study were selected, on the basis of a preliminary screen, from several which react with EMA. The comparison has enabled us to show that the less desirable features of the staining with the polyclonal antiEMA' (that is, the heterogeneity and the staining of metaplastic cells) was due to the expression of its epitope and not due to any vagaries in the antiserum 
itself. Of course, we hoped that one of the monoclonal antibodies might give as good, if not better, discrimination between normal and abnormal smears. In the event, these antibodies did not stain dyskaryotic cells as consistently as the polyclonal antiserum and this would rule out consideration of their use for diagnosis since the over-riding criterion for a reagent is that there should be no false negatives. On the positive side, this study has confirmed that there is a substance(s) which is expressed more strongly in neoplasias, including malignancy, and so this approach towards finding new reagents which might assist automated diagnostic screening is worth pursuing.

We thank Professor AM Neville for his help and encouragement, Mrs K Steele for supplying reagents, and Dr IC Summerhayes for the gift of the monoclonal antibodies. This work was supported by grants from the Cancer Research Campaign and the Medical Research Council.

\section{References}

' Sloane JP, Ormerod MG. Distribution of epithelial membrane antigen in normal and neoplastic tissues and its value in diagnostic tumour pathology. Cancer 1981;47:1786-95.

${ }^{2}$ Sloane JP, Hughes F, Ormerod MG. An assessment of the value of epithelial membrane antigen and other epithelial markers in solving diagnostic problems in tumour histopathology. Histochem J 1983;15:645-54.

${ }^{3}$ Sloane JP, Ormerod MG, Carter RL, Gusterson BA, Foster CS. An immunohistochemical study of the distribution of epithelial membrane antigen in normal and disordered squamous epithelium. Diagnostic Histopathology 1982;5:11-7.

4 Bamford PN, Ormerod MG, Sloane JP, Warburton M. An immunohistochemical study of the distribution of epithelial antigens in the uterine cervix. Obstet Gynecol 1983;61:63-8.

${ }^{5}$ Moncrieff D, Ormerod MG, Coleman DV. Immunohistochemical staining of cervical smears for epithelial membrane antigen. Anal Quant Cytol 1984 (in press).

- Moncrieff D, Ormerod MG, Coleman DV. Tumour marker studies in cervical cytology. Potential for automation. Acta Cytol 1984 (in press).

7 Ormerod MG, Steele K, Westwood JH, Mazzini NM. The partial purification and properties of epithelial membrane antigen. $\mathrm{Br}$ J Cancer 1983;48:533-41.

${ }^{8}$ Jha RS, Wickenden C, Anderson MC, Coleman DV. Br J Obstet Gynaecol 1984 (in press).

- Husain OAN, Page-Roberts B, Miller J. A sample preparation for automated cervical screening. Acta Cytol 1978;22:15-21.

${ }^{10}$ Heyderman E, Steele K, Ormerod MG. A new antigen on the epithelial membrane: its immunoperoxidase localisation in normal and neoplastic tissues. J Clin Pathol 1978;32:35-9.

"To A, Dearnaley DP, Omerod MG, Canti G, Coleman DV. Indirect immunoalkaline phosphatase staining of cytologic smears of serous effusions for tumour marker studies. Acta Cytol 1983;27:109-13.

${ }^{12}$ Chang SE, Taylor-Papadimitriou J. Modulation of phenotype in cultures of human milk epithelial cells and its relation to the expression of membrane antigen. Cell Differentiation 1983; 12:143-54.

${ }^{13}$ Mcgee JO' D, Woods JC, Ashall F, Bramwell ME, Harris H. A new marker for human cancer cells. 2. Immunohistochemical detection of the $\mathrm{Ca}$ antigen in human tissues with the $\mathrm{Cal}$ antibody. Lancet 1982;ii: 7-10.

${ }^{14}$ Edwards PAW, Brooks I, Monaghan P. Expression of epithelial antigens in primary cultures of normal human breast analysed with monoclonal antibodies. Differentiation 1984;25:247-58.

15 Haines HG, McCoy JP, Hofheinz DE, Ng ABP, Nordqvist SRB, Leif RC. J Natl Cancer Inst 1981;66:465-74.

${ }^{10}$ Sincock AM, Middleton J, Moncrieff D. Towards an automated procedure for the quantitative screening of cervical neoplasms. J Clin Pathol 1983;36:535-8.

Requests for reprints to: Dr MG Ormerod, Institute of Cancer Research, The Haddow Laboratories, Clifton Avenue, Sutton, Surrey SM2 5PX, England. 